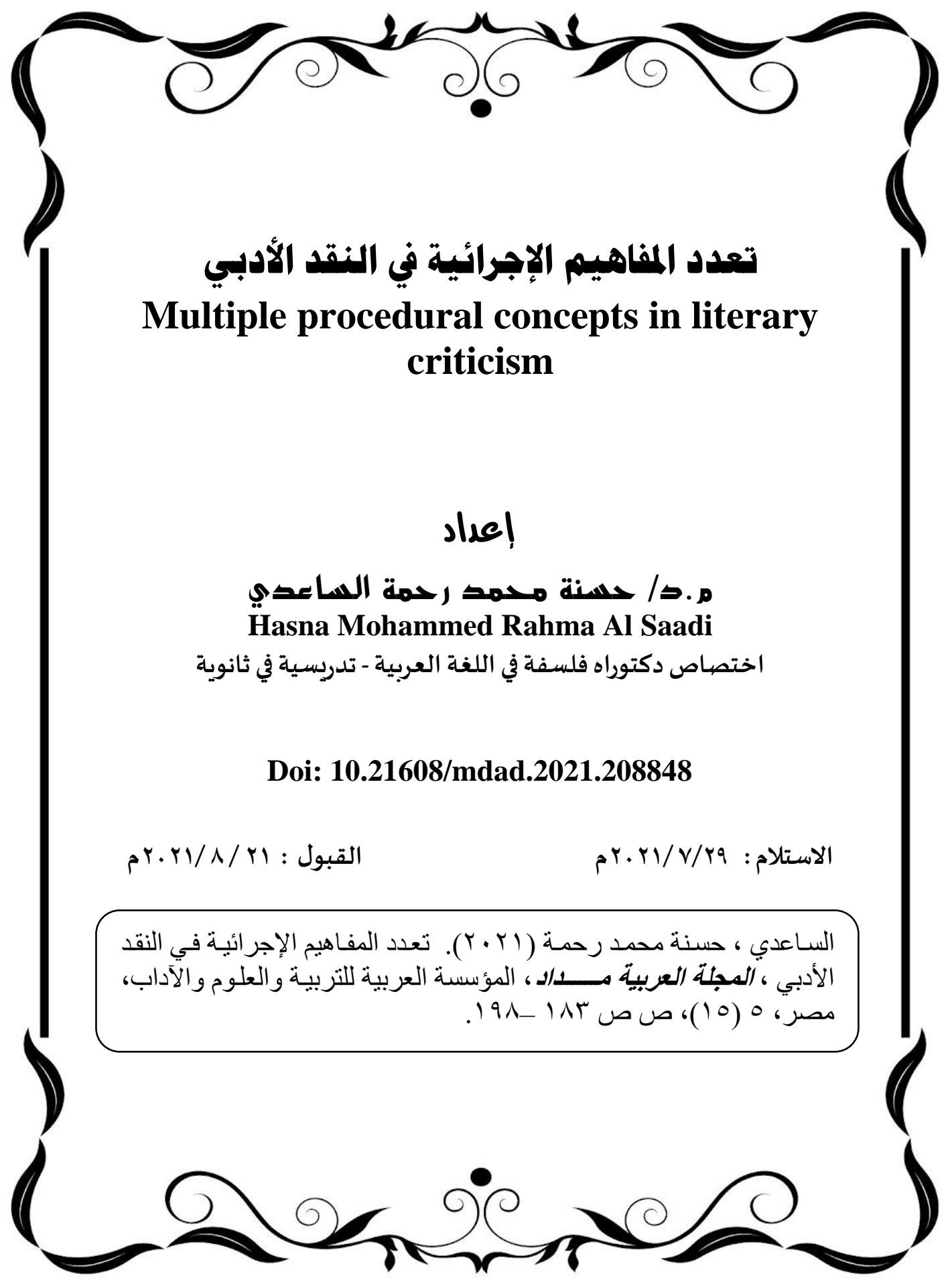




\section{تعدد المفاهيم الإجرائية في النقد الأدبي}

ان ما ينبغي تأكيده في هذا المجال أن تكون مصطلحاتنا منطلقة من فهم عميق

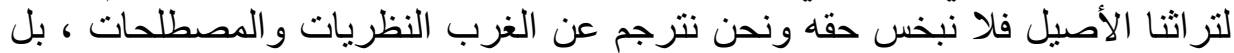

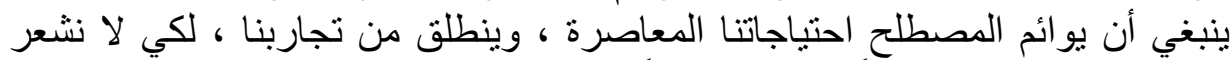

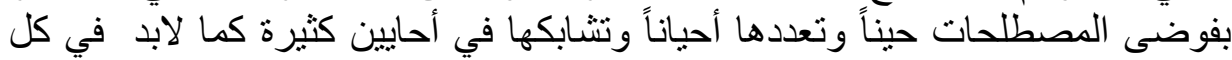

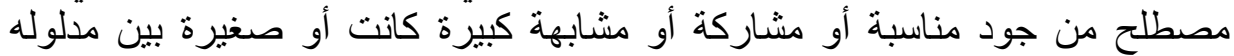

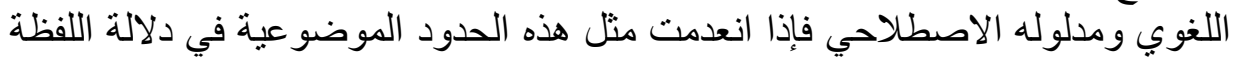

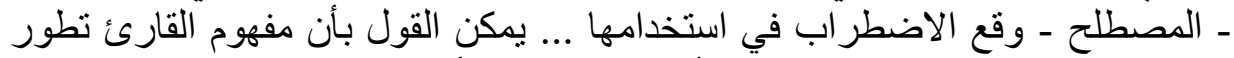

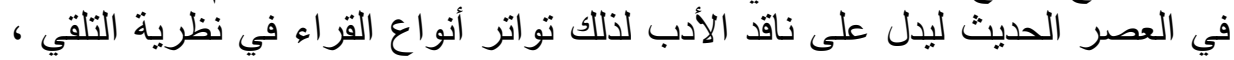

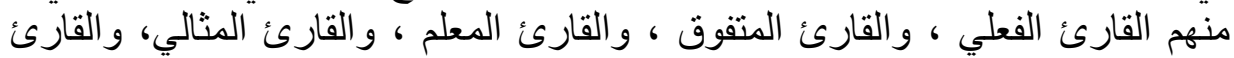

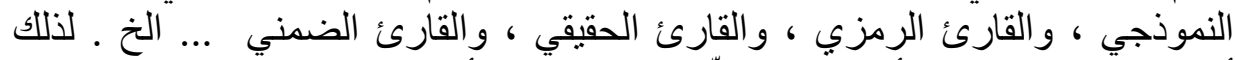

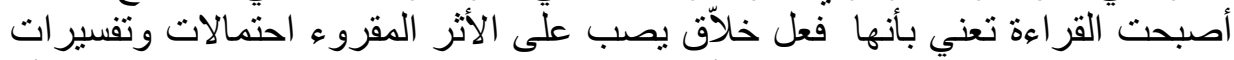

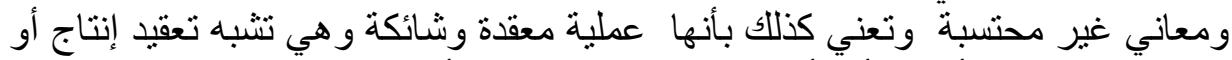

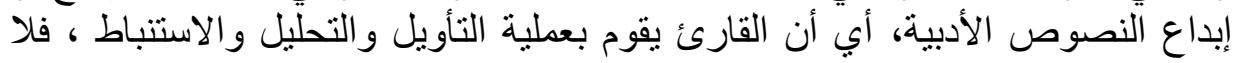

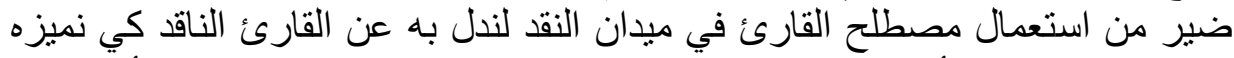

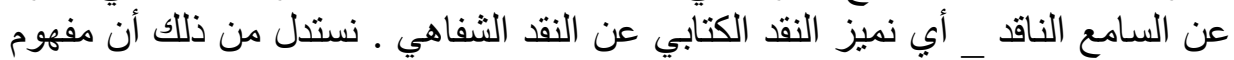

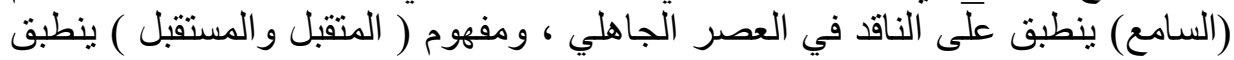

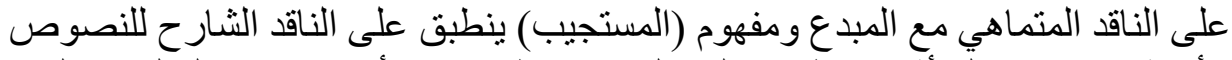

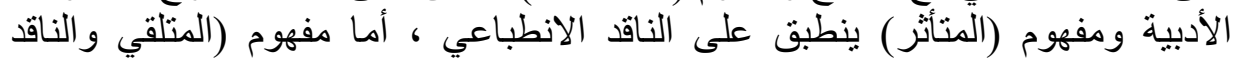

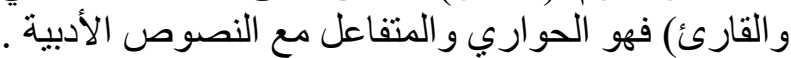
الكلمات الافتتاحية : المفاهيم الإجرائية ، النقد الادبي ، الأبئية المتلقي ، الناقد ، و القارئ .

\section{Abstract:}

What should be emphasized in this field is that our terminology should be based on a deep understanding of our original heritage, so that we do not underestimate its right when we translate theories and terminology from the West. As it has to be in everyA term from the presence of an occasion, participation, or similarity, big or small, between its linguistic meaning and its idiomatic meaningIt can be said that the concept of the reader has developed in the modern era to indicate the literary critic, so the frequency of the types of readers in the theory of reception, 
including the actual reader, the superior reader, the teacher reader, the ideal reader, the typical reader, the symbolic reader, the real reader, and the implicit reader...etc. Therefore, reading has come to mean that it is a creative act that affects the reading effect with uncalculated possibilities, interpretations and meanings. It also means that it is a complex and thorny process, which is similar to the complexity of the production or creativity of texts. Literary. That is, the reader performs the process of interpretation, analysis and deduction, so there is no harm in using the term reader in the field of criticism to refer to the critical reader in order to distinguish him from the critical listener - that is, to distinguish written criticism from oral criticism. We infer from this that the concept of (the listener) applies to the critic in the pre-Islamic era, the concept of (the receiver and the future) applies to the critic who is identified with the creator, the concept of (the respondent) applies to the critic who explains literary texts, the concept of (the affected) applies to the impressionistic critic, and the concept of (the receiver and the critic) And the reader) is the dialogue Interacting with literary texts.

Keywords :Procedural concepts, hearer, receiver, criticizer and reader .

المقدمة

نقصد بالمفاهيم الإجرائية المصطلحات التي تعالج النصوص الأدبية وقد

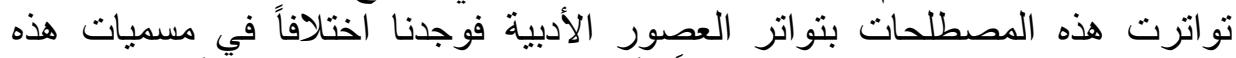

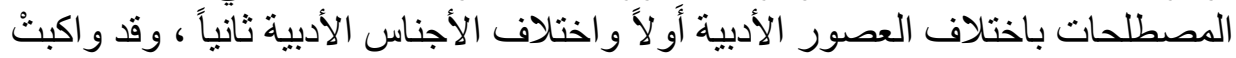

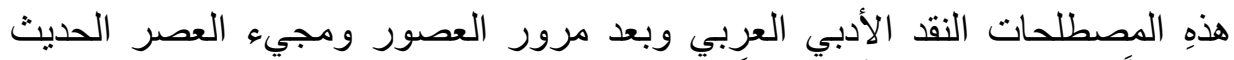

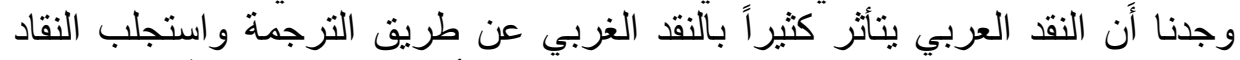

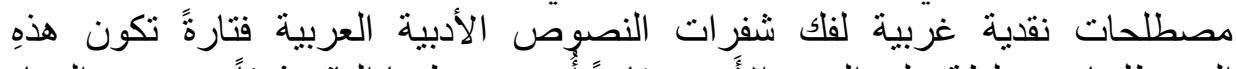

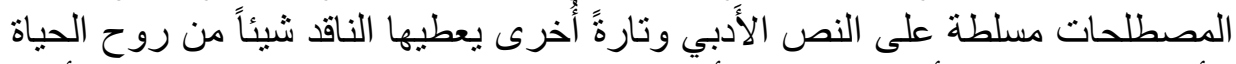

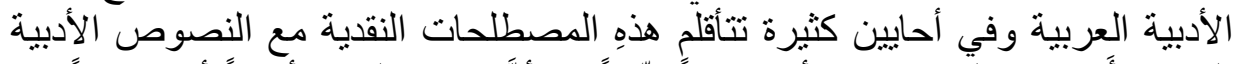

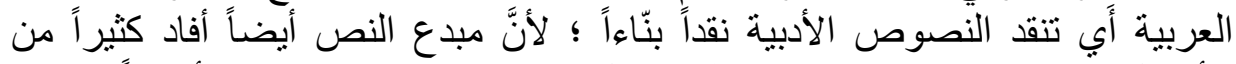

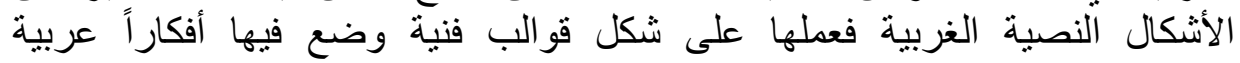




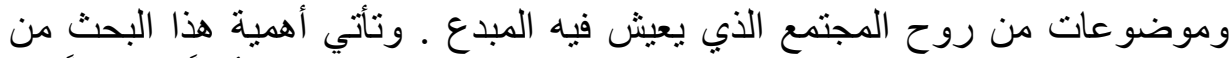

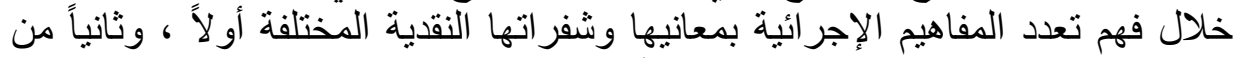

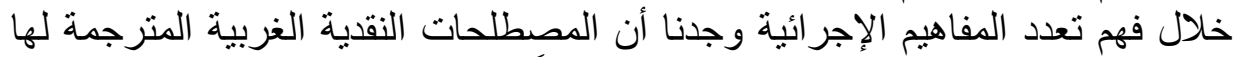

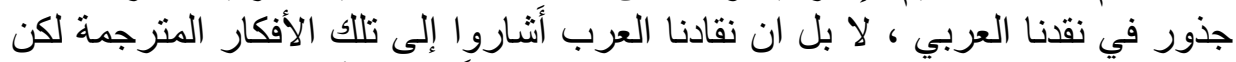

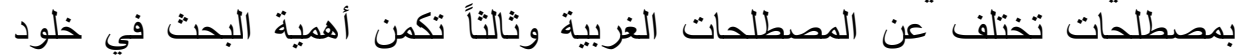

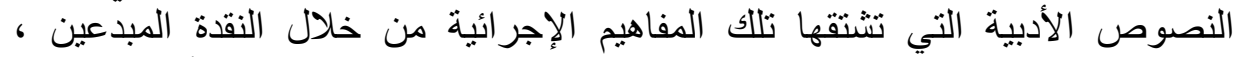

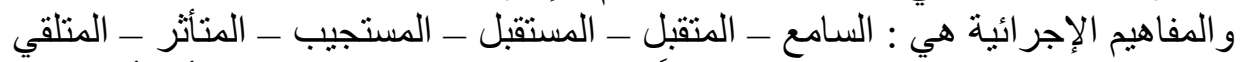

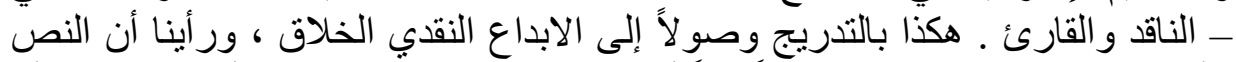

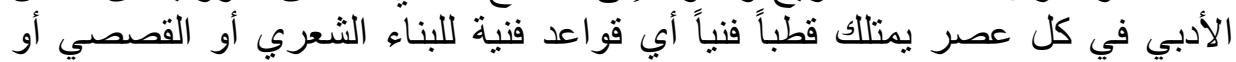

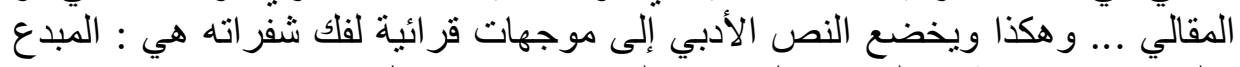

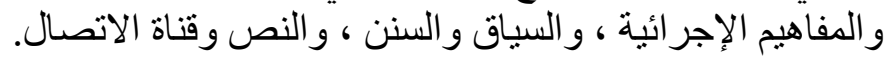

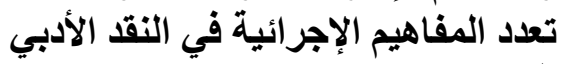
المفاهيم الإجر ائية لقد تواردت مفاهيم إجرائية عدة لمن يتلقى النصوص بحسب قربها من الابداع

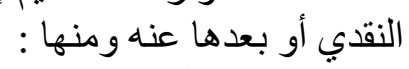

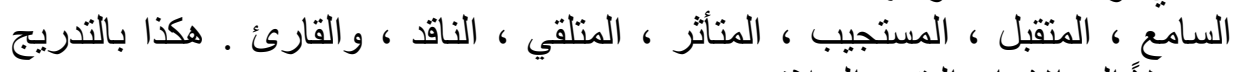

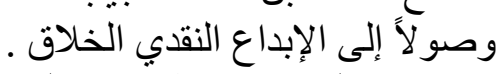

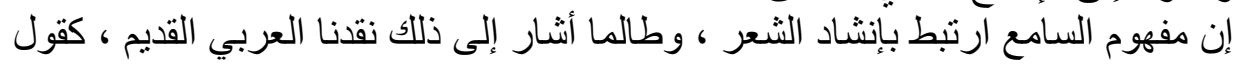

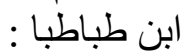

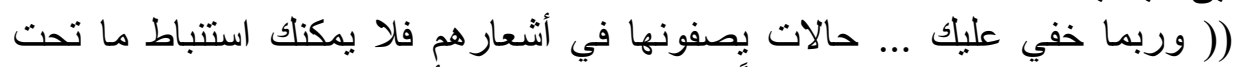

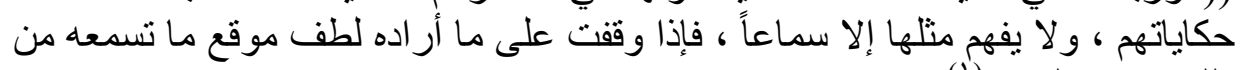

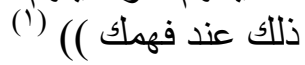
السامع لقد كان السامع في العصر الجاهلي يطرب لذلك (( الإنشاد التعبيري .... الذي الذي

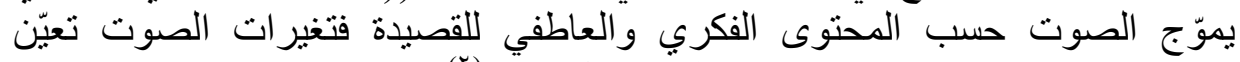

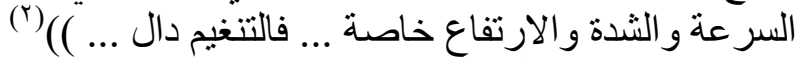

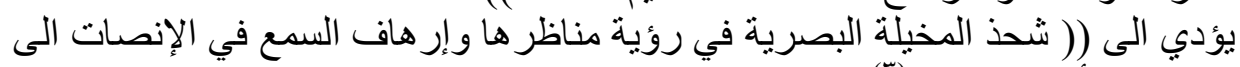

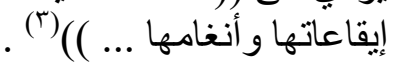

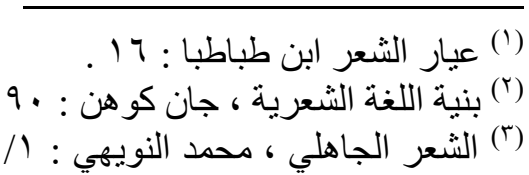

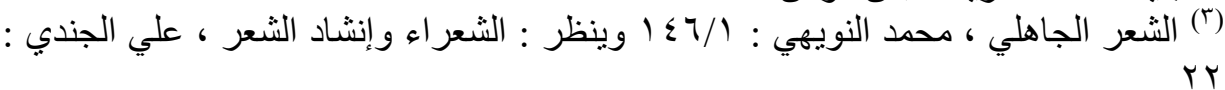




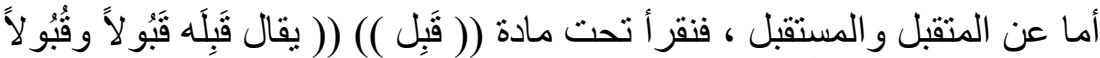

المتقبل و المستقبل

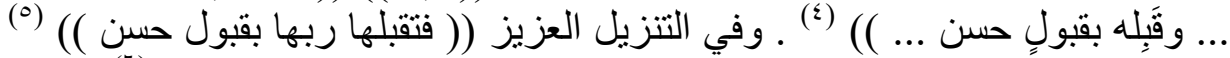

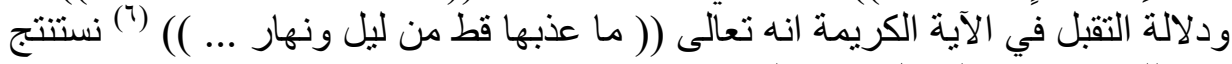

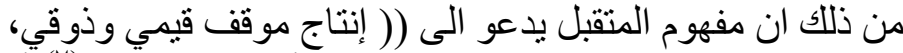

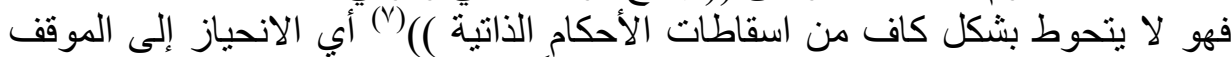

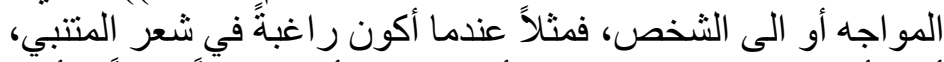

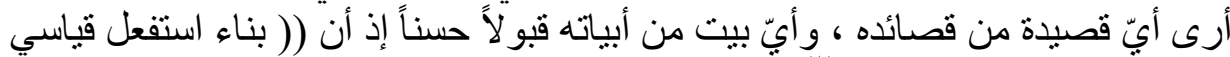

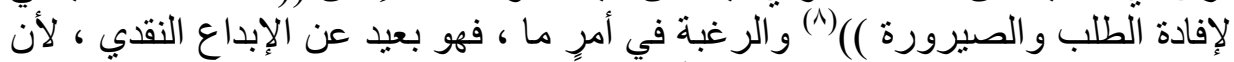

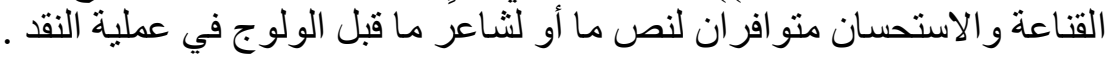

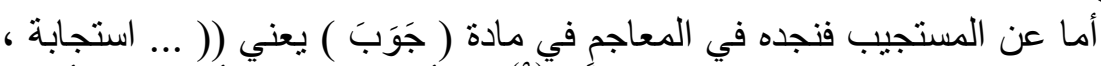
المستجيب

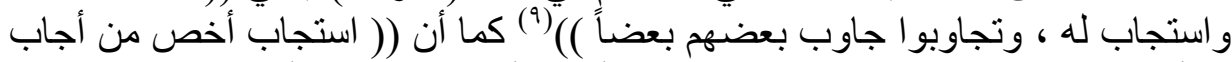

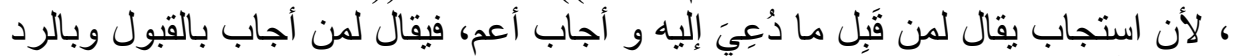

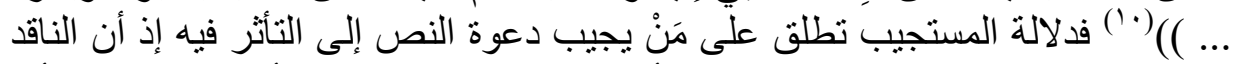

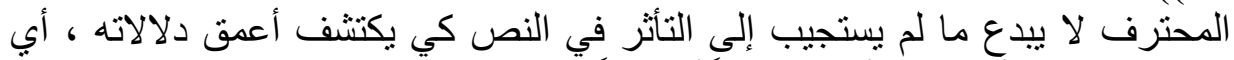

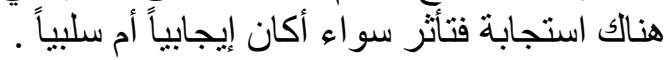
المتأثر

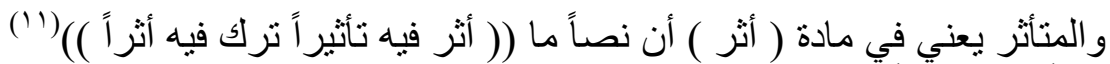

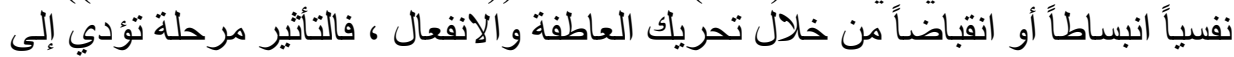

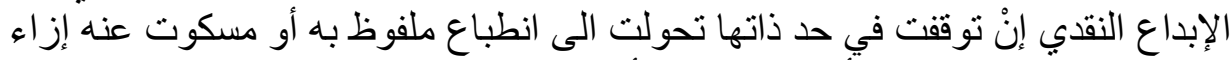

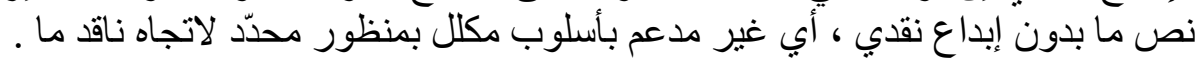

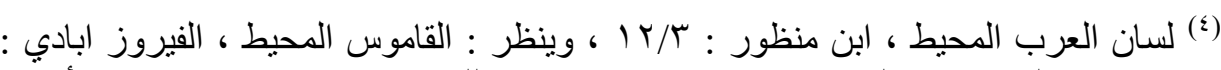

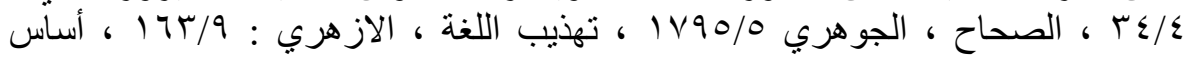

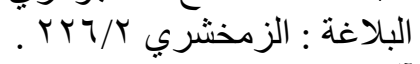

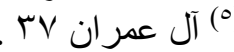

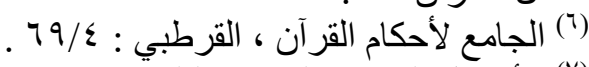

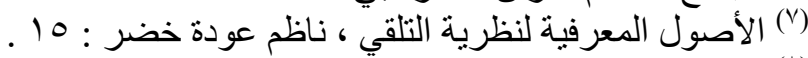

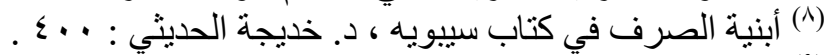

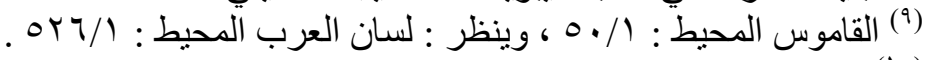

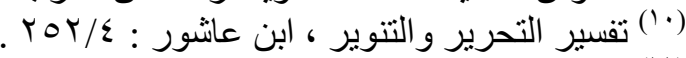

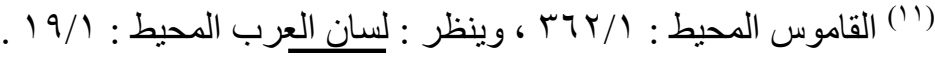




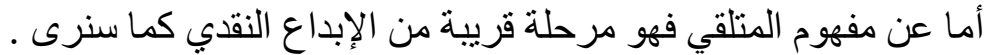

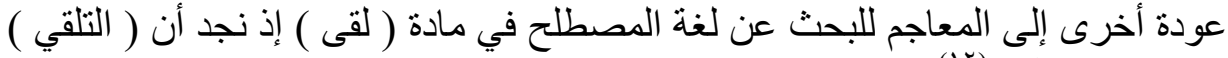

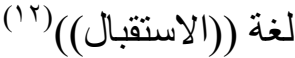

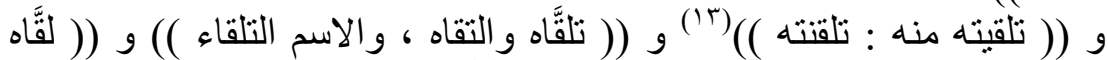

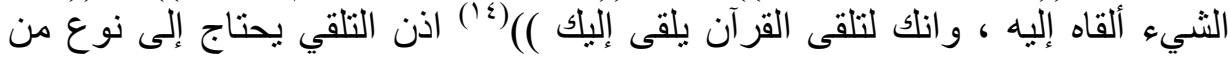

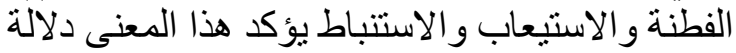

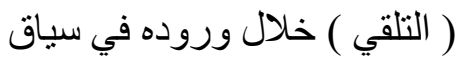

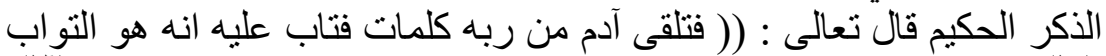

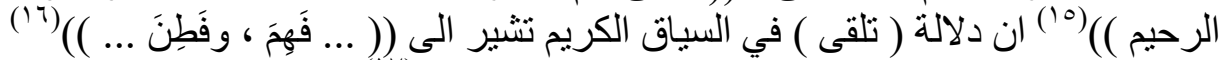

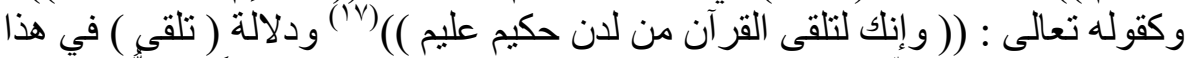

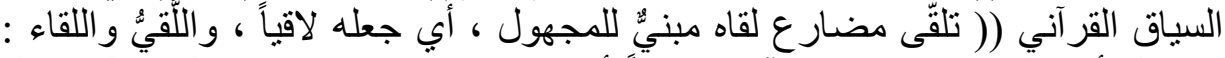

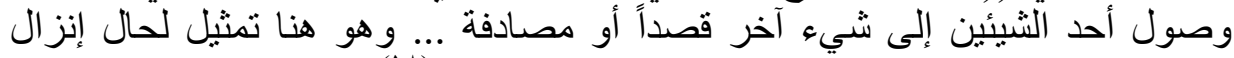

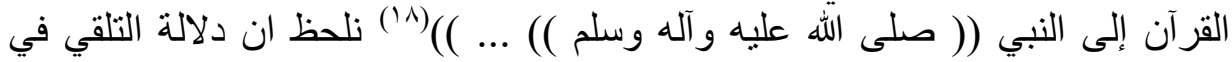

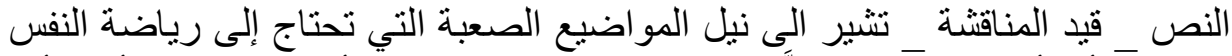

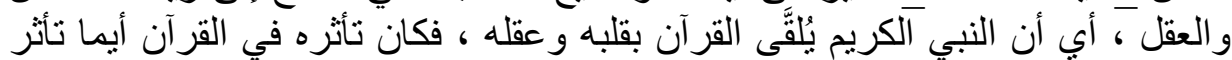

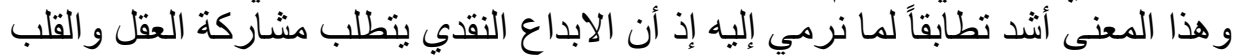

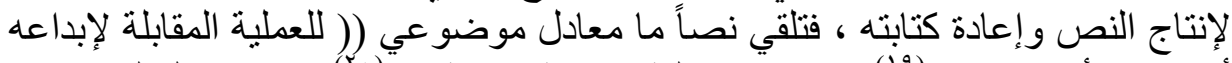

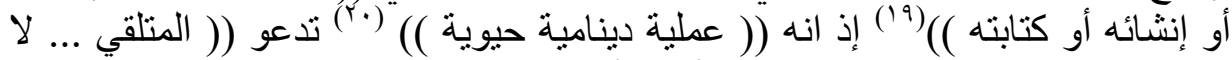

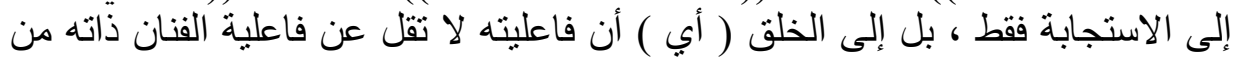

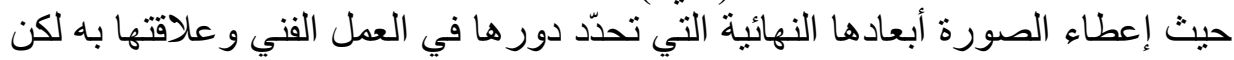

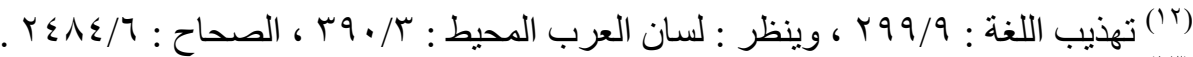

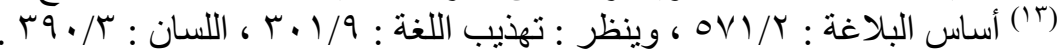

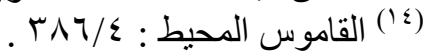
TV: البقرة

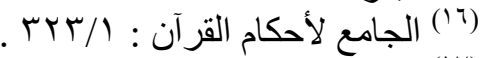
(lv)

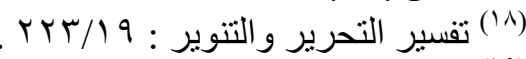

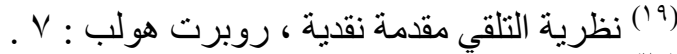

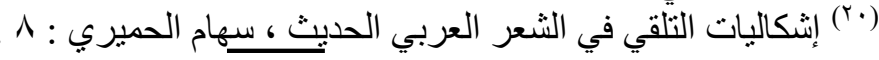


دور الفنان أيضاً يؤكد ، فالفنان الذي يعجز عن تحقيق التناغم بين وظيفتي الصورة

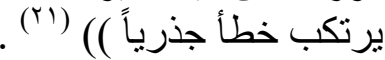

ينبغي في هذا الصدد تعيين (( مهمة المتلقي إزاء الكتابة المختلفة ، هي مهمة مركبة ...

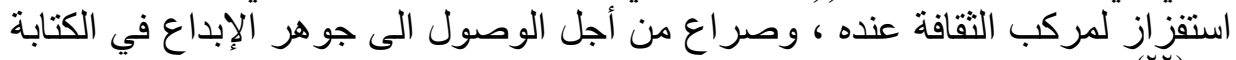

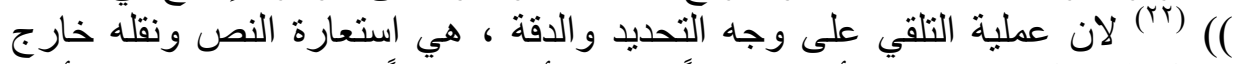

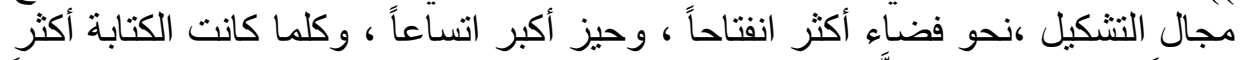

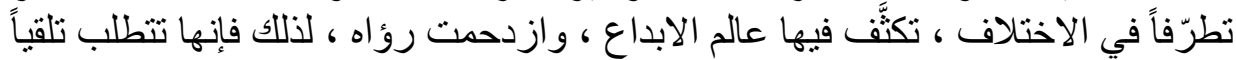
أكثر ذكاء.

نستدل من ذلك أن المتلقي يمثل مرحلة متقدمة نحو الإبداع النقدي فالمصطلح

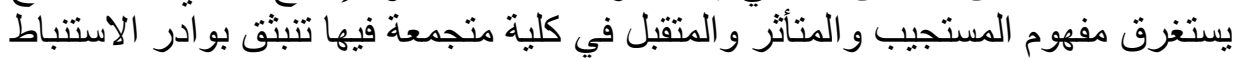

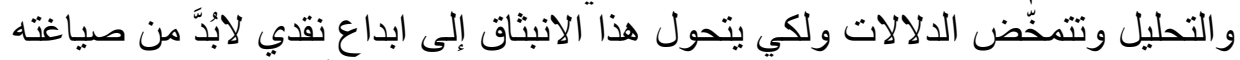

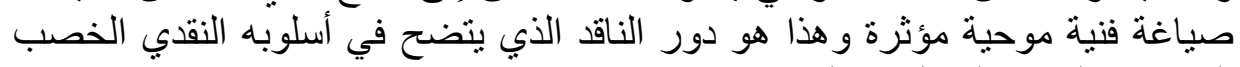

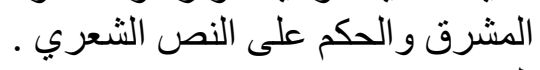

الناقد

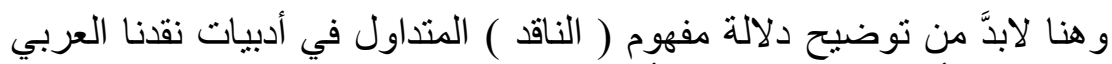

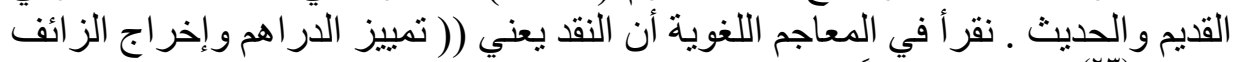

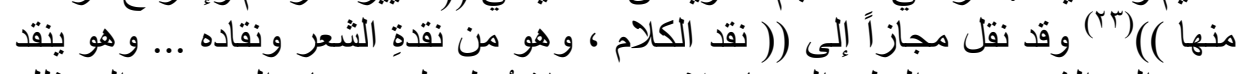

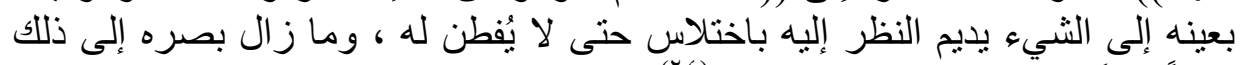

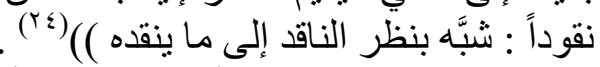

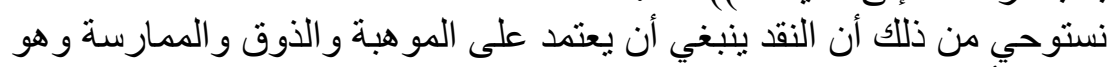

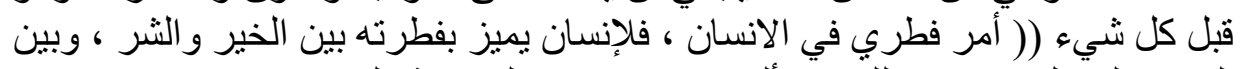

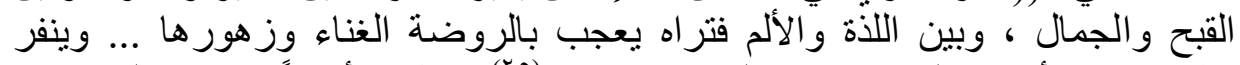

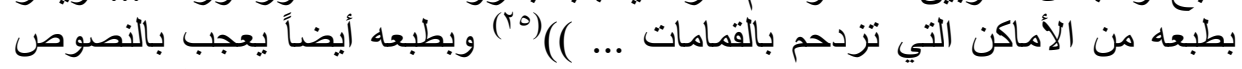

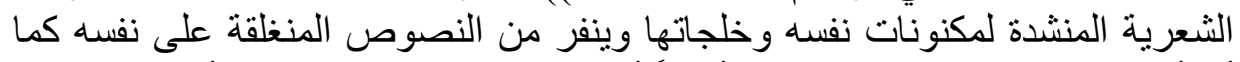

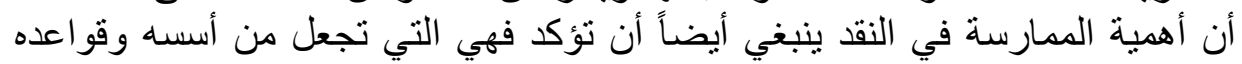

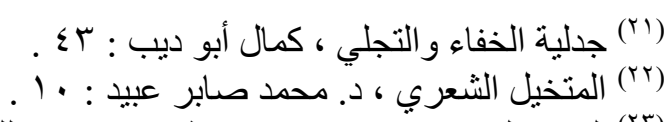

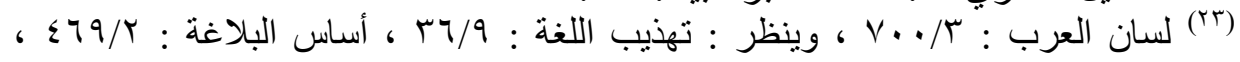

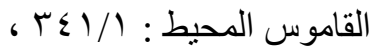

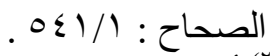

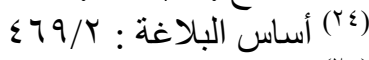

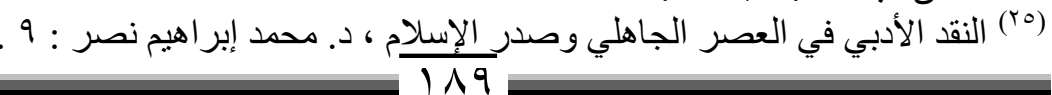


نامية مع نمو النصوص أو الأنو اع الجديدة على مر العصور كما أنها تربط بين الأصول

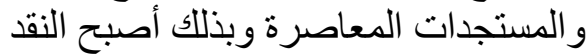

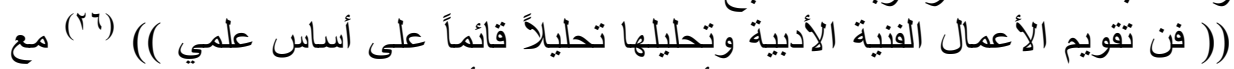

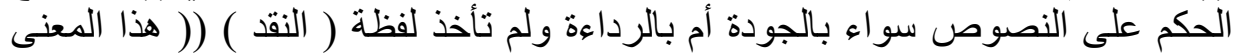

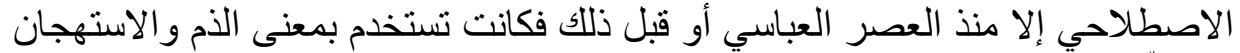

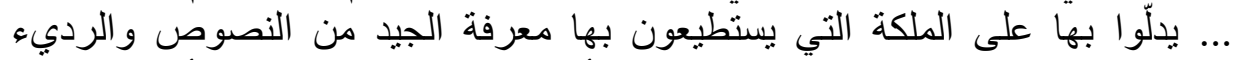
و الجميل و القبيح وما تتتجه هذه الملكة في الأدب من ملاحظات وآراء وله وأحكام مختلفة

$\left.{ }^{(r V}\right)(($

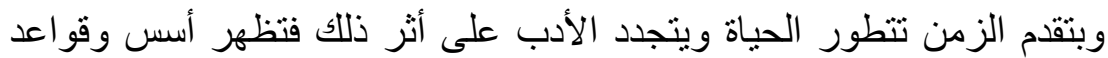

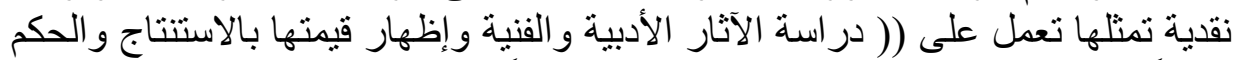

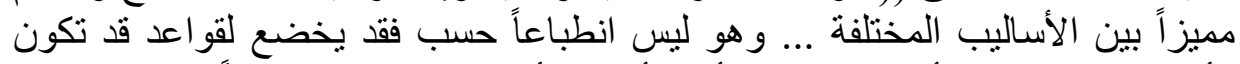

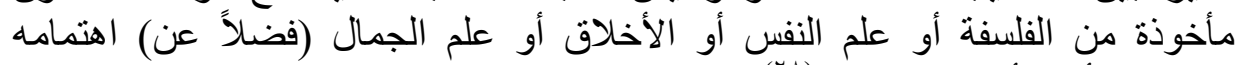

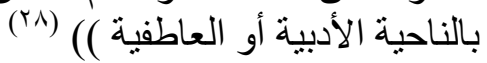

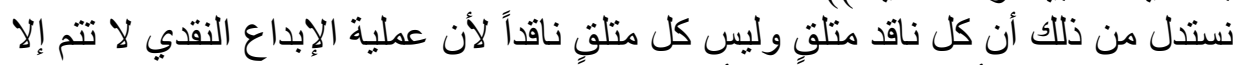

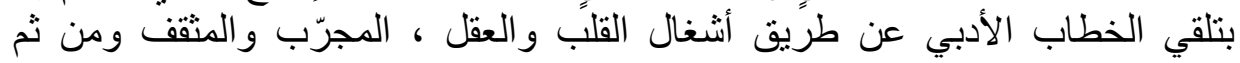
در استه وتحليله و الحكم عليه . القارئ

أما عن مفهوم القارئ المتداول في النقد الحديث نسأل عن جدارته كمفهوم يؤدي (أناء

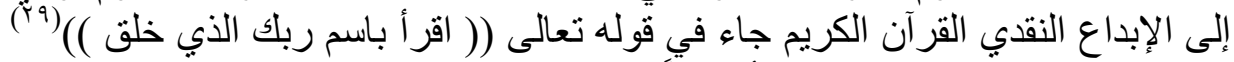

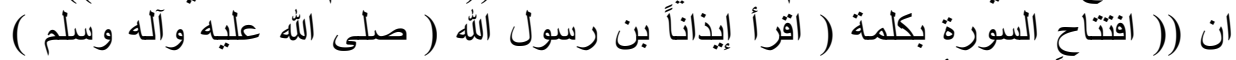

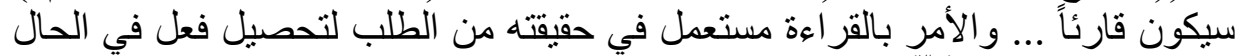

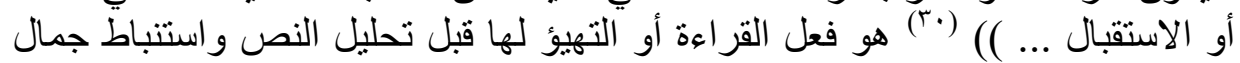

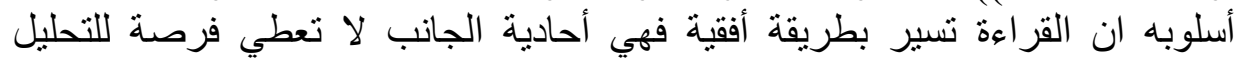

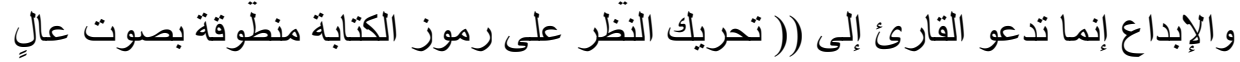

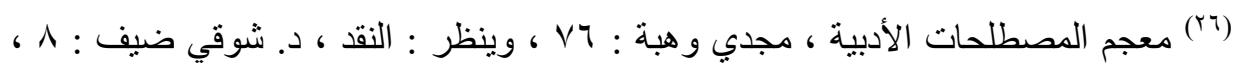

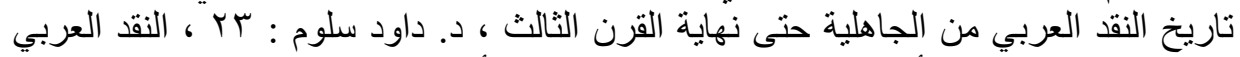

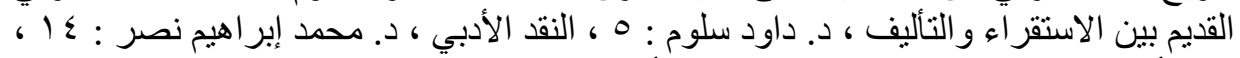

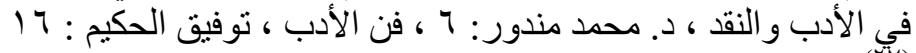

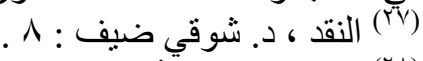

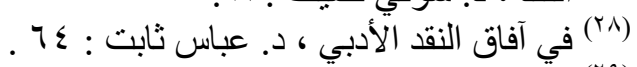
(199)

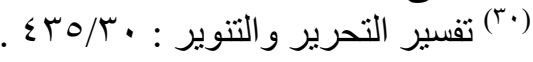




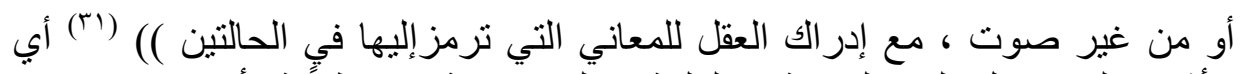

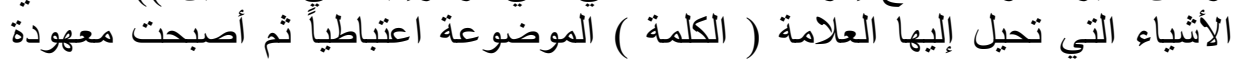

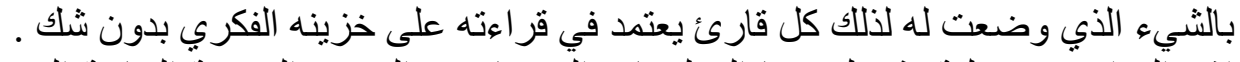

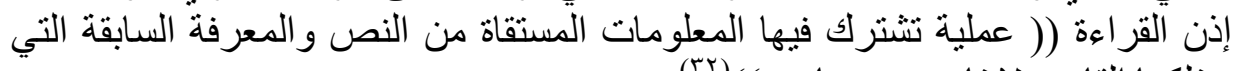

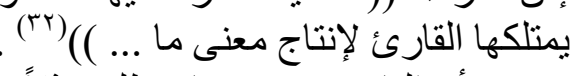

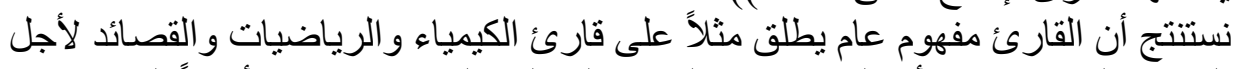

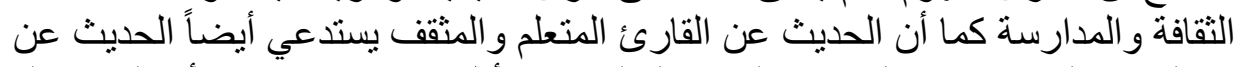

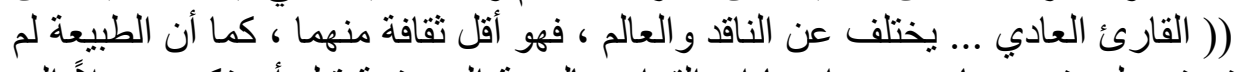

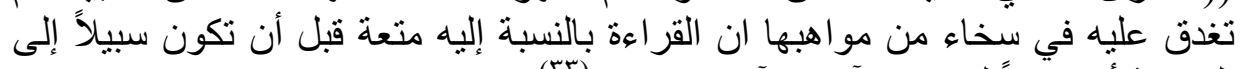

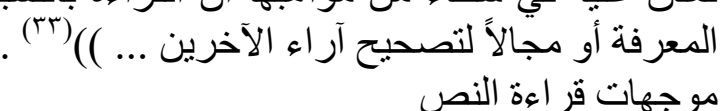

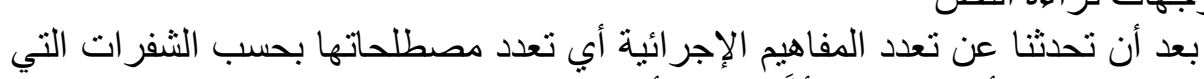

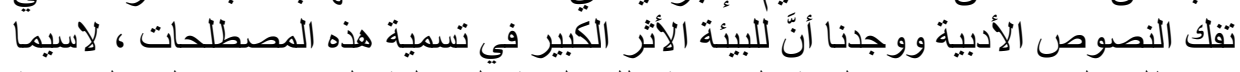

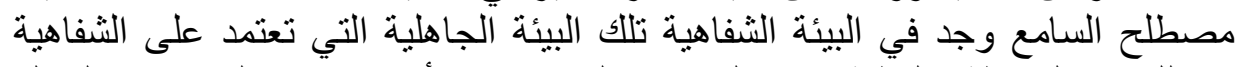

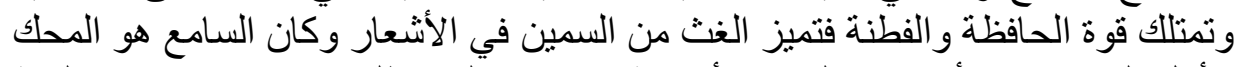

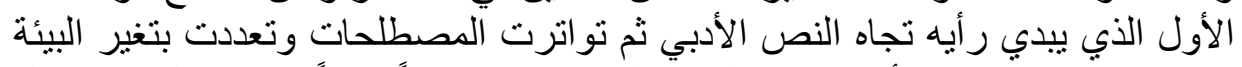

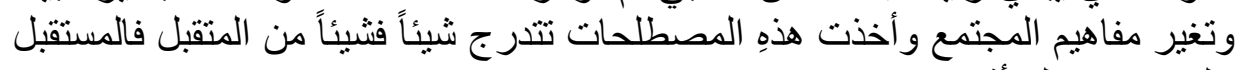

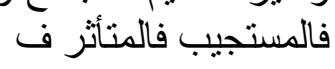

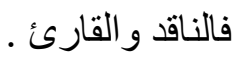

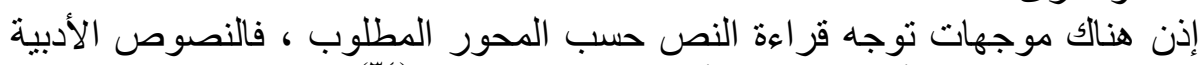

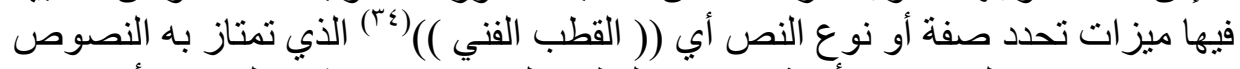

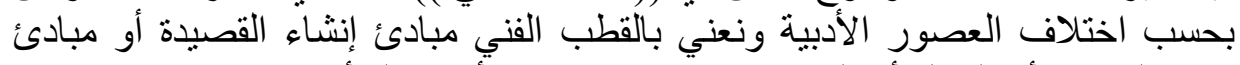

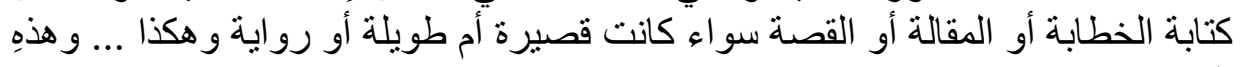

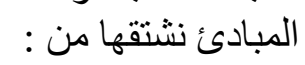

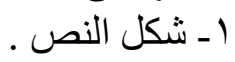

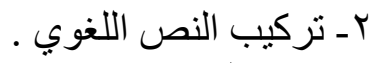

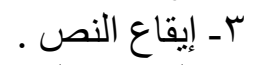

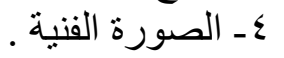

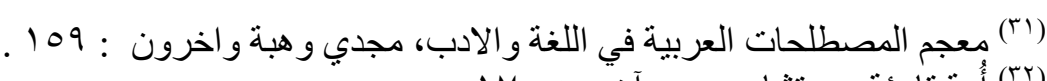

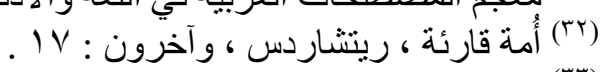

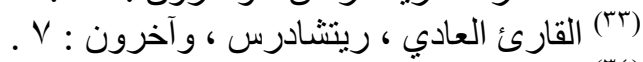


هـ مضمون النص أو أفكاره .

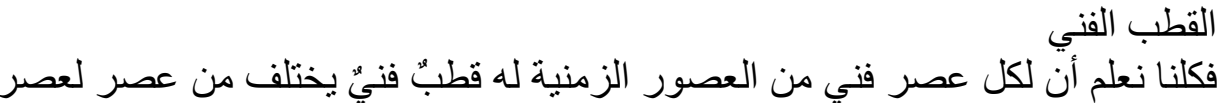

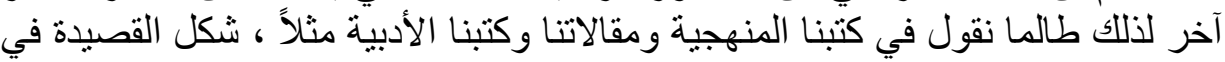

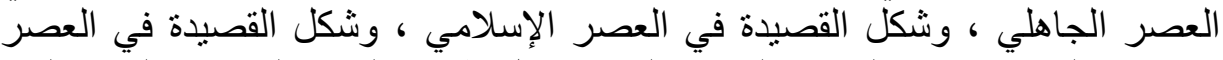

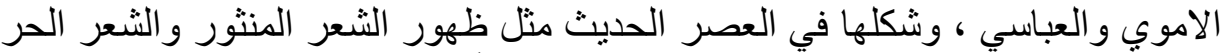

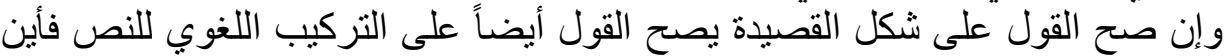

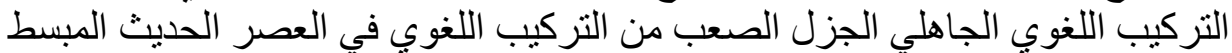

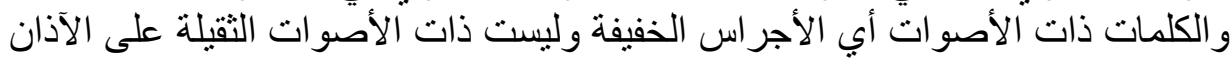

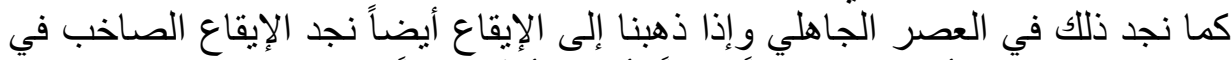

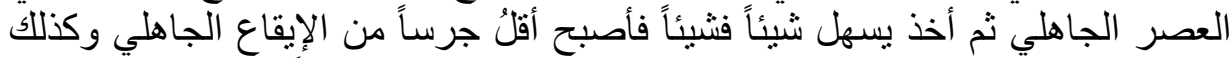

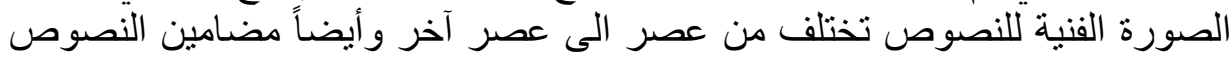

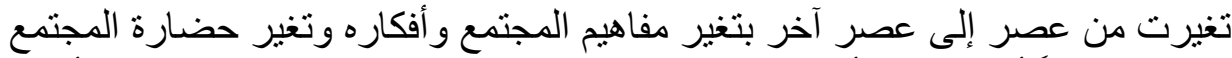

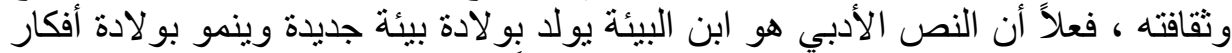

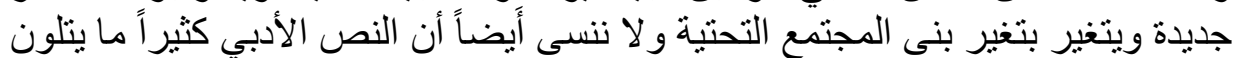

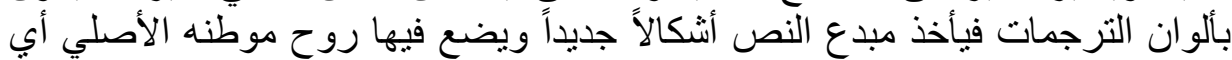

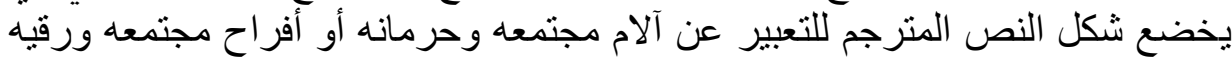
و وهكا.

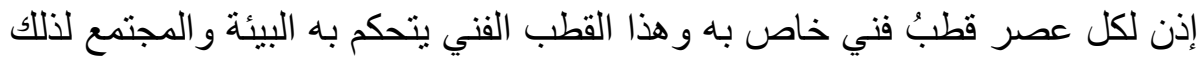

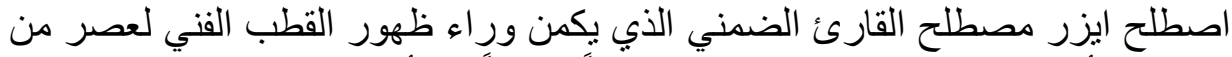

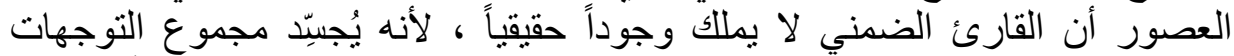

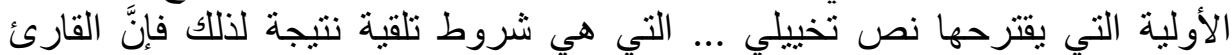

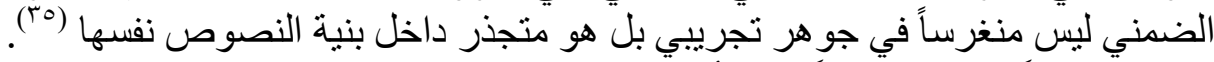

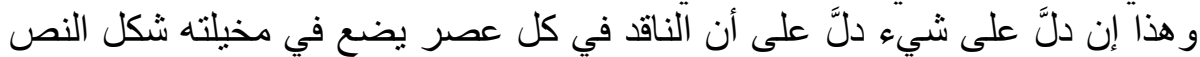

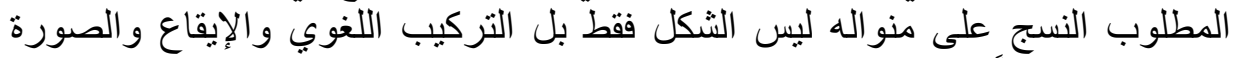

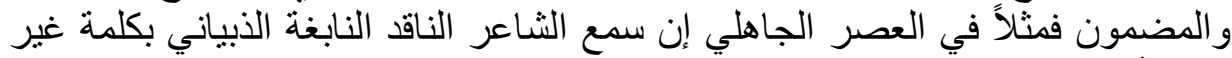

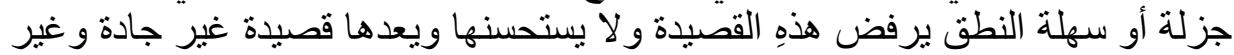

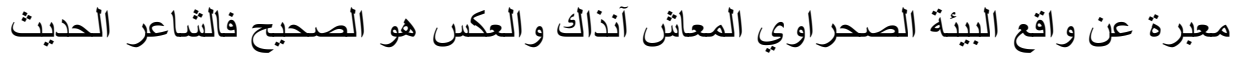

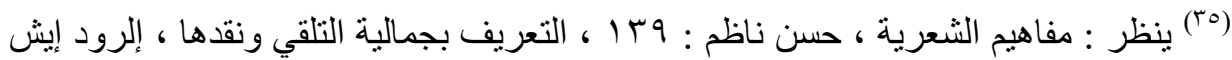

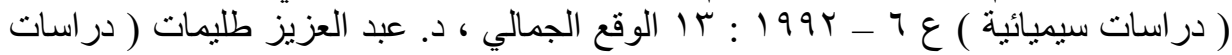


أو شاعر اليوم إذا استعمل الفاظ جاهلية صعبة جزلة نشعر وكأننا نقرأ شعر أ غريباً بعيداً

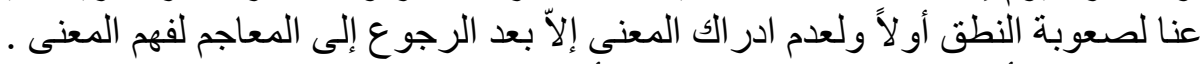

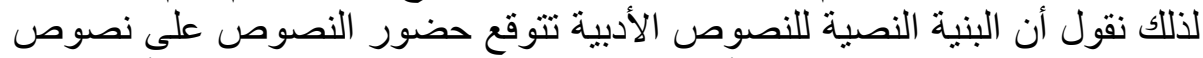

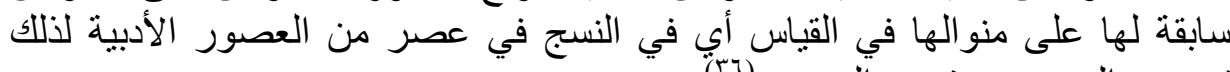

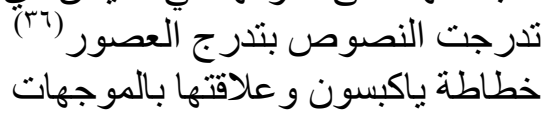

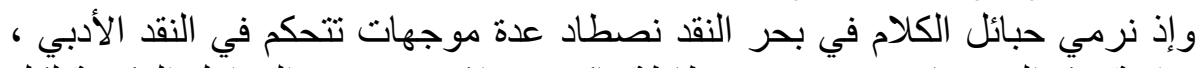

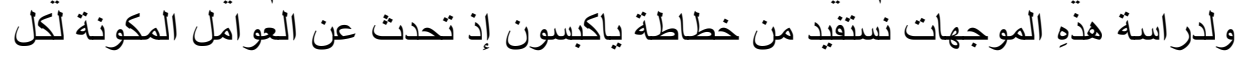
سيرورة لسانية ولكل فعل تو اصلي لفظي : لنطي سياق

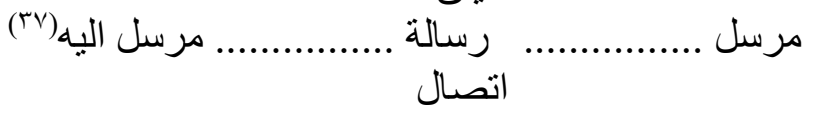

سنن

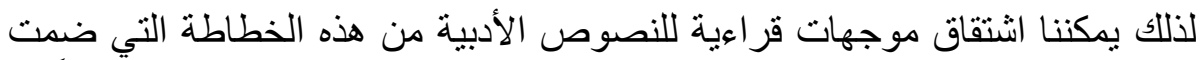

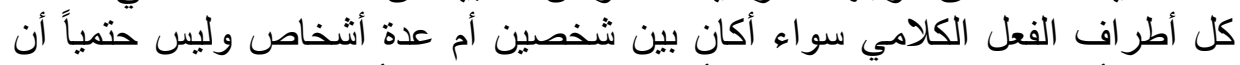

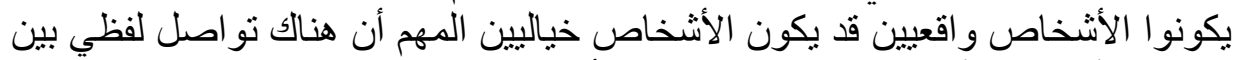

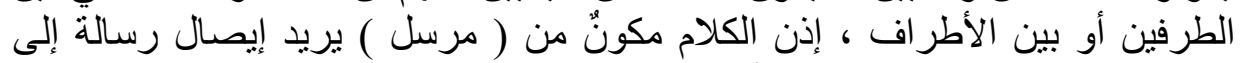

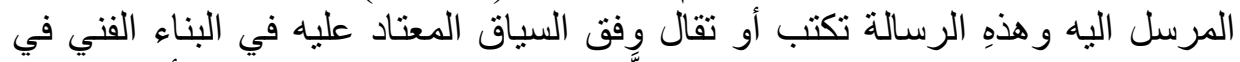

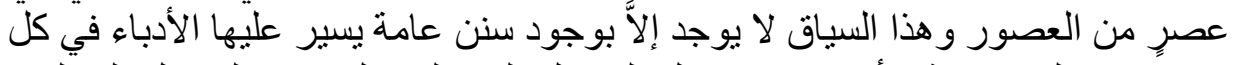

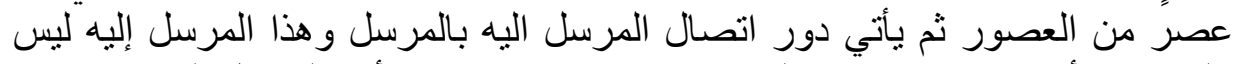

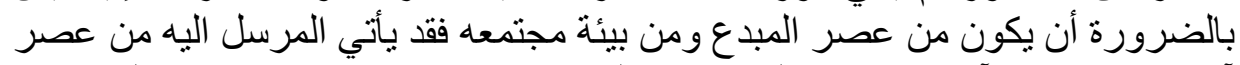

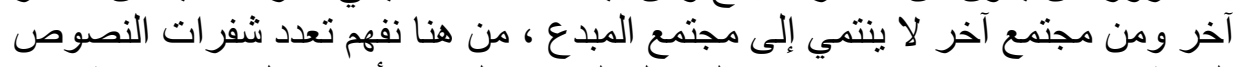
النقدية واختلافها وتنو عها باختلاف المرسل إلى إليه في كل مرة أو في كل شفرة نقدية يشتق

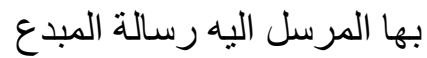

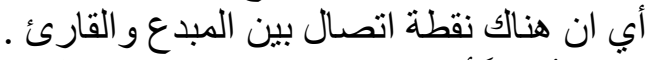

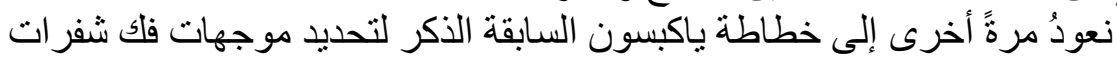

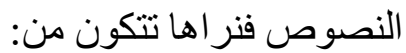

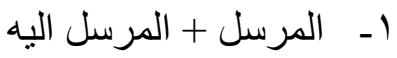

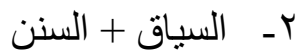




$$
\text { ب- الرسالة + الاتصال }
$$

هذهِ هي المحاور الستة لياكبسون يمكن أن تختزل الألى ثلاثثة محاور لدر اسة موجهات قر اءة النصوص الأدبية فنقول :

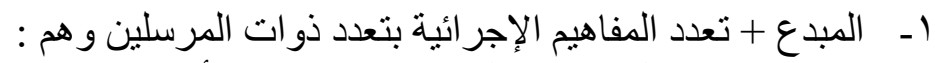

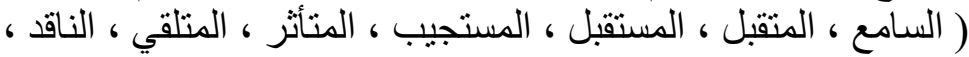

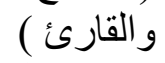

r- السياق المعتاد عليه في البناء + سنن السياق أي قو اعد البناء الفني في كل

$$
\text { عصر من العصور. }
$$

r- النص + قناة الاتصال ( شفاهية كما في العصر الجاهلي أو كتابية كما في

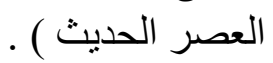

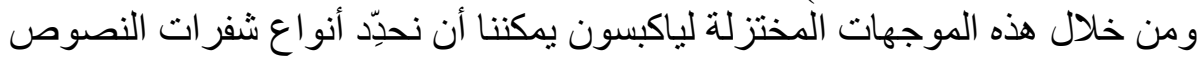

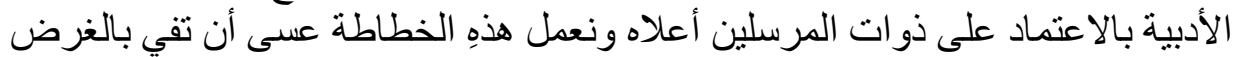

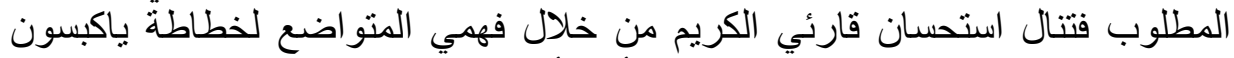

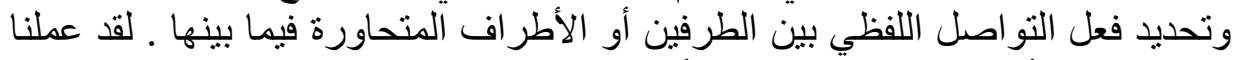
خطاطة تبين أنواع النقد الذي يدرس أو يفهم ويشق شفر الأر الت النصوص الإبداعية التي

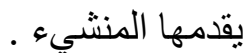

(६)

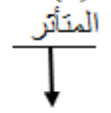

الناقَد

الانطباعي بنفل

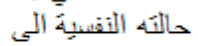

النص أي فزحه

وحزنه
(T)

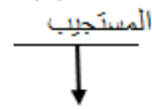

الناقد

التـارح لموضوضوع

النصن منتاك في

كتبنا المنهجيَّة

بتسزح النصوص الأدبية
(T)

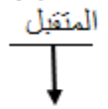

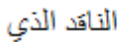

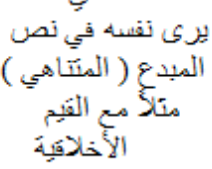

(०)

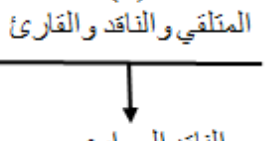

(1)

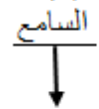

$$
\text { الناقَد }
$$

الجاهلي

التنفاهي

بحكم الناقَد بكلمنين أو اكتر

$$
\text { الناقد الحواري }
$$

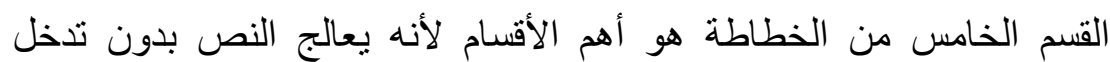

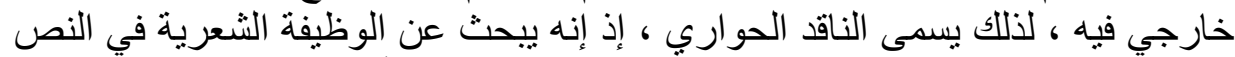

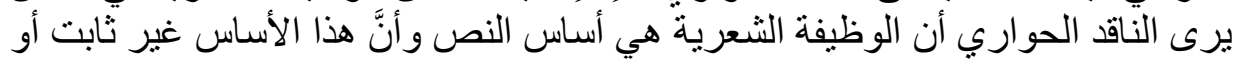
محدد بل متغير على مر العصور ومتلون بلون كل عصر حسب التغيرات الني الجذرية 
للإطار السوسيو ثقافي (^^) عموماً ، رأى الدكتور شجاع مسلم العاني : (( إنَّ الوظيفة

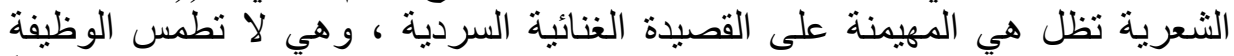

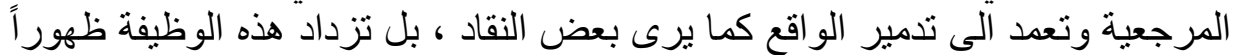

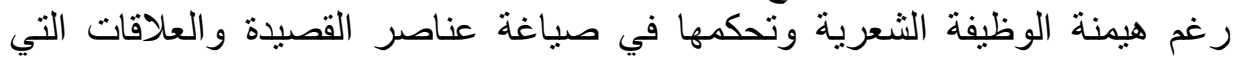

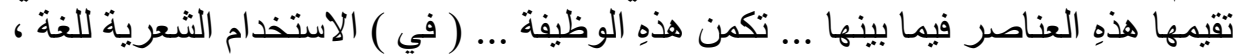

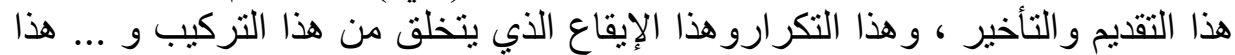

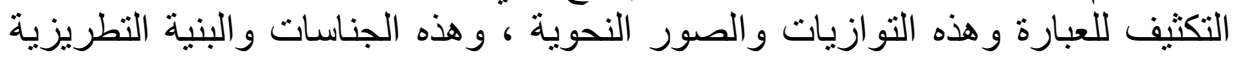

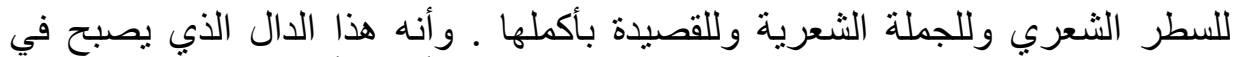

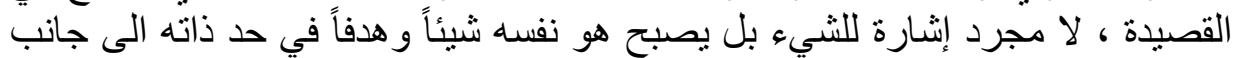

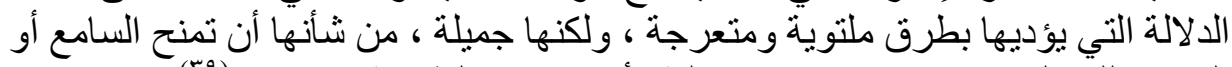

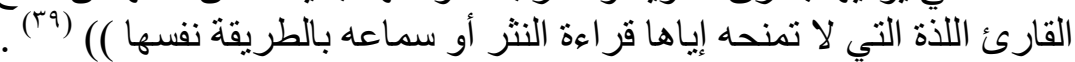

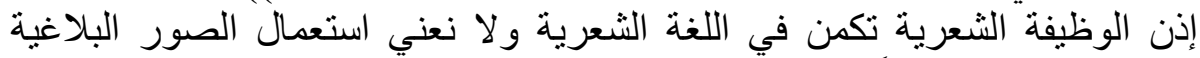

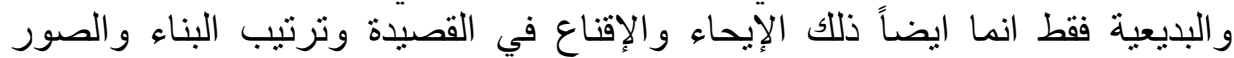

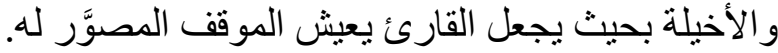

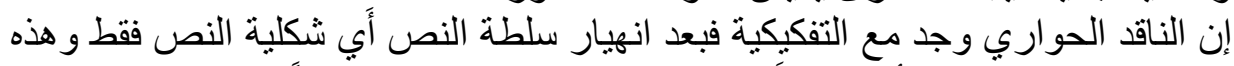

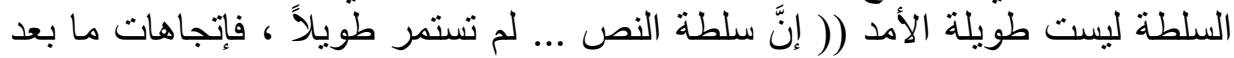

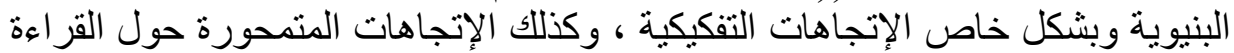

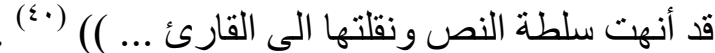

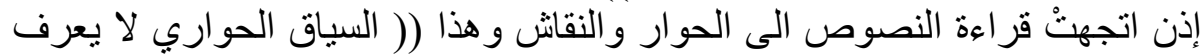

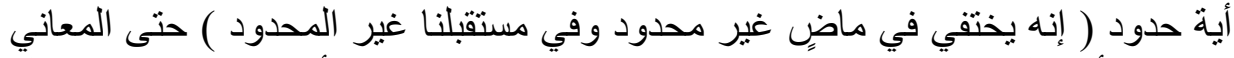

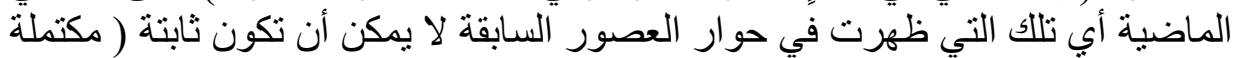

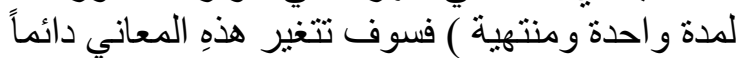

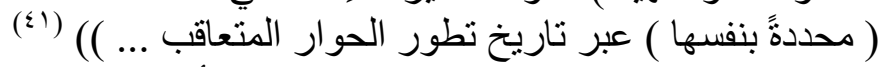

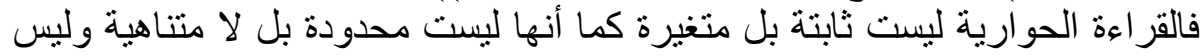

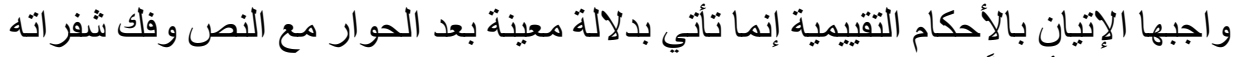
و هذه الدلالة أيضاً متغيرة مع كل حوار التعة إنمان 
- ـ آفاق في الأدب والنقد _ د. عناد غزوان _ بغداد _ دار الثؤون الثقافية العامة - - أبنية الصرف في كتاب سيبويه _ د. خديجة الحديثي _ بغداد _ منشور ات مكتبة

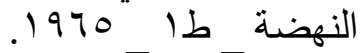

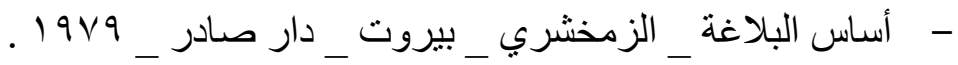

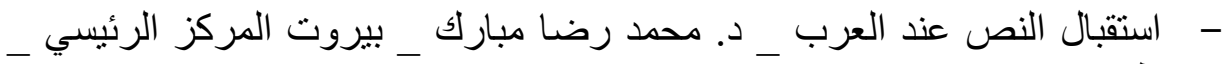
طا 1997 - الأصول المعرفية لنظرية التلقي _ ـناظم عودة خضر _ _الأردن _ _عمان _ مطبعة

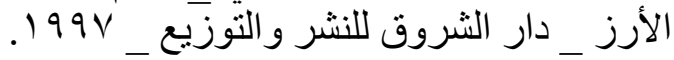

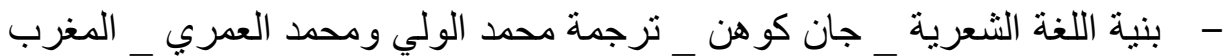

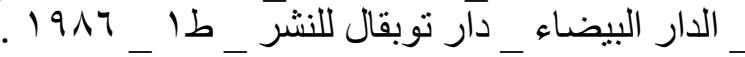

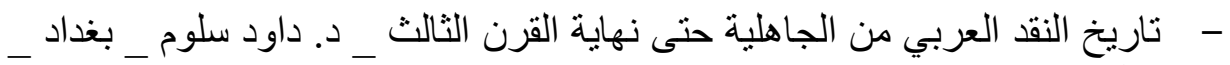

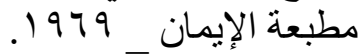

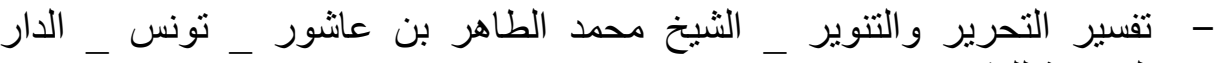

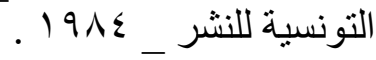

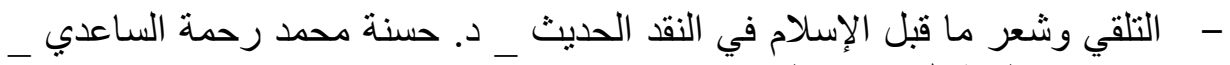

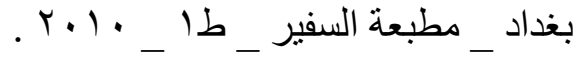

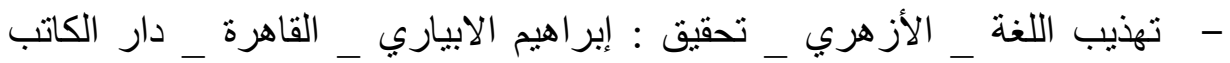

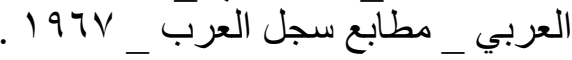

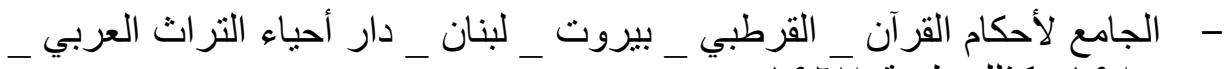
1970 1970 - - جدلية الخفاء و التجلي در اسات بنيوية في الثعر _ _ كمال أبو ديب _ بيروت _ _ دار

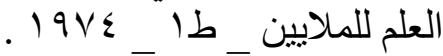
- الثعر الجاهلي _ منهج في دراسته وتقويمه _ د. محمد النويهي _ القاهرة _ _الناشر

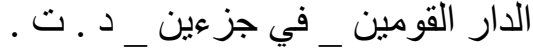

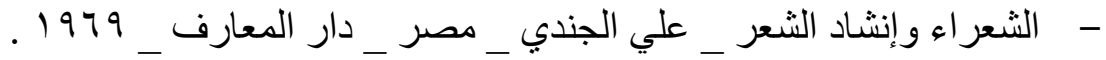




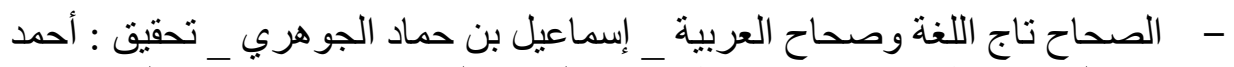

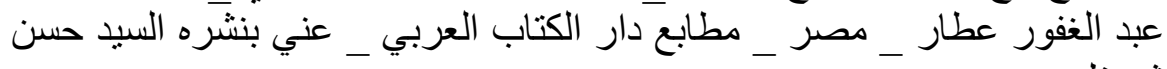

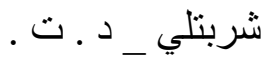

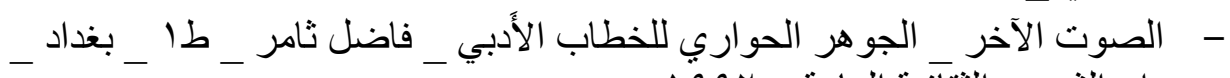

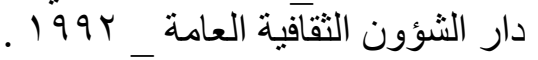

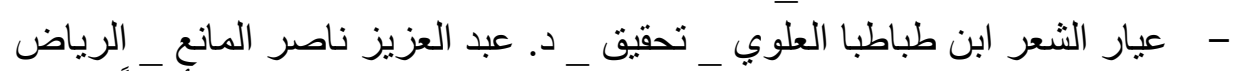

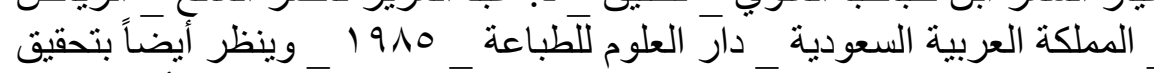

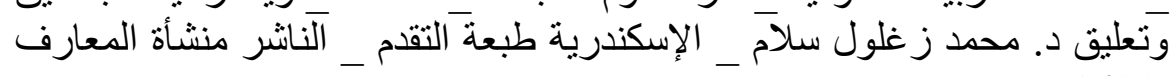
$.19 V \mathrm{~V}$

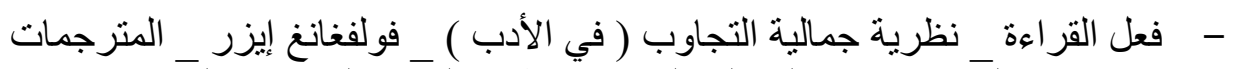

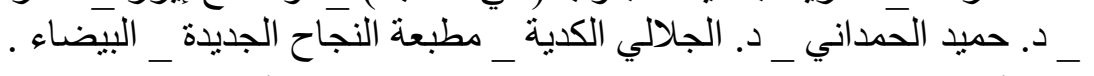

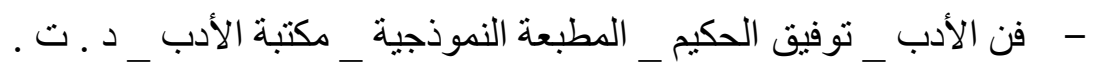

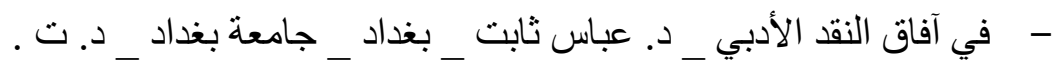

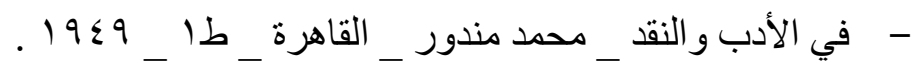

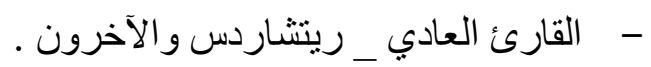

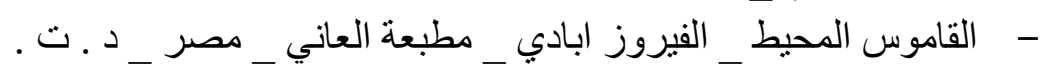

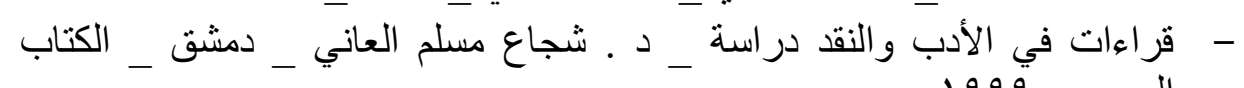

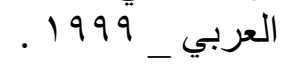

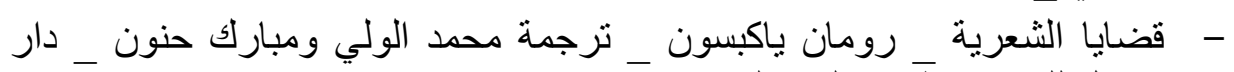

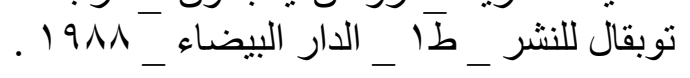

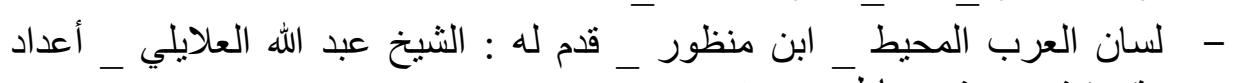

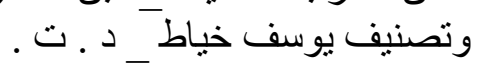

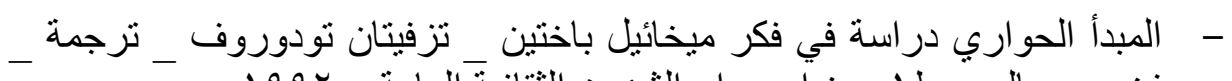

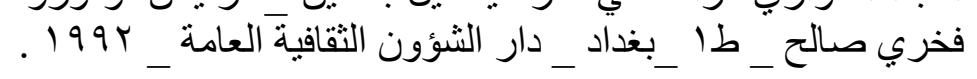

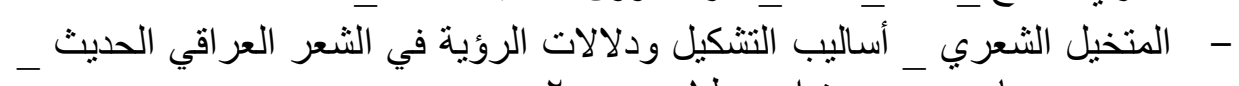

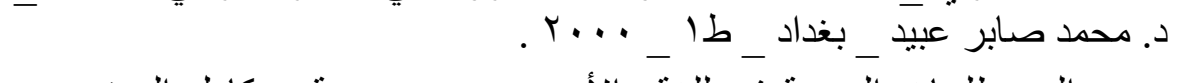

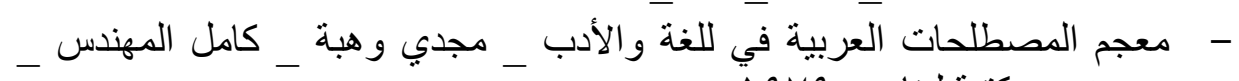

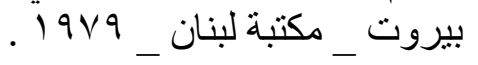




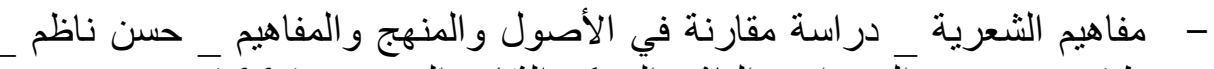

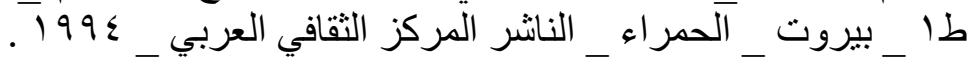

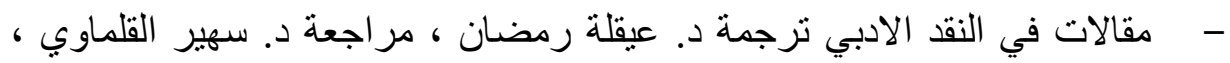

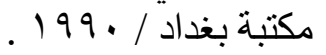

- - نظرية التلقي _ مقدمة نقدية _ روبرت هولب _ _ترجمة : د. د. عز الدين إسماعيل .

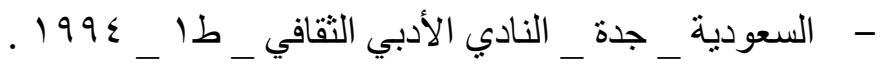

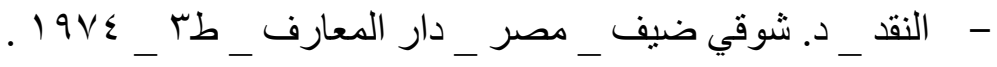

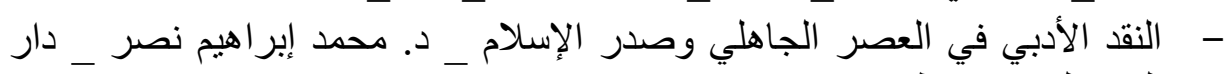

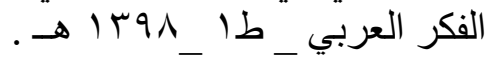

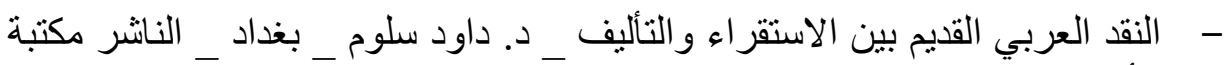

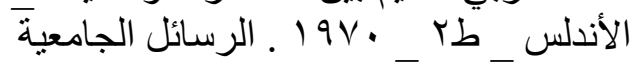

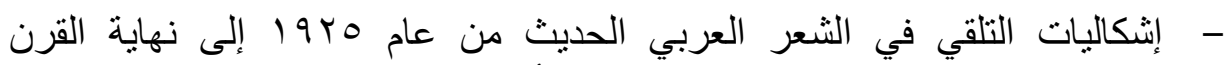

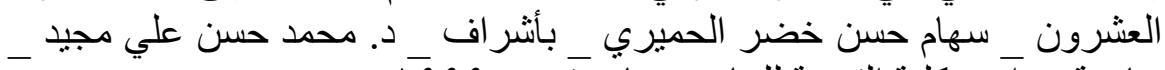
جامعة بغداد _ كلية التربية للبنات _ ماجستير _

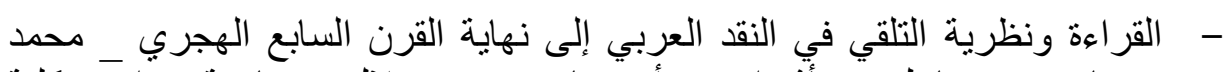

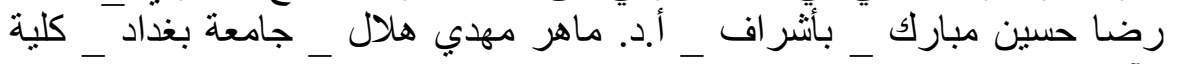

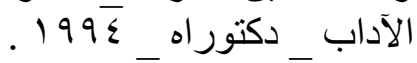
المجلات والدوريات

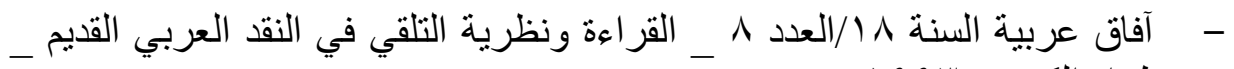

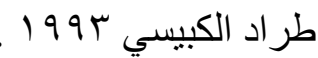

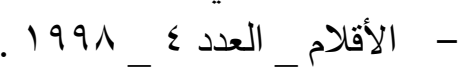

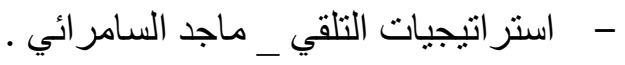

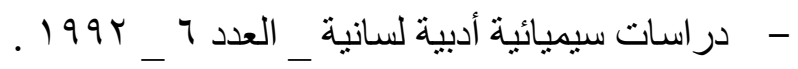
- - التعريف بجمالية التلقي ونقدها _ التلقي الأدبي _ إلرود إيش _ _ترجمة محمد برادة.

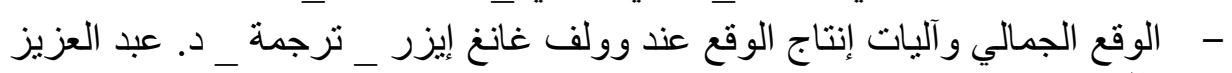

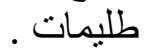

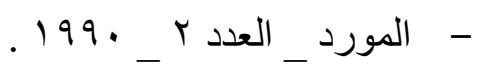

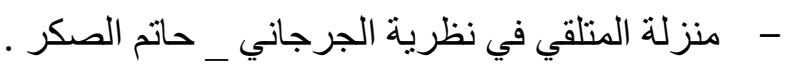

